\title{
Direct Hemoperfusion Using Immobilized Polymyxin B in Patients with Rapidly Progressive Interstitial Pneumonias: A Retrospective Study
}

\author{
Shintaro Hara ${ }^{a}$ Hiroshi Ishimoto $^{a}$ Noriho Sakamoto $^{a}$ Hiroshi Mukae $^{c}$ \\ Tomoyuki Kakugawa $^{a}$ Yuji Ishimatsu ${ }^{a}$ Mariko Mine $^{b}$ Shigeru Kohno ${ }^{a}$ \\ ${ }^{a}$ Second Department of Internal Medicine, Nagasaki University School of Medicine, and ${ }^{b}$ Division of Scientific \\ Data Registry, Biostatistics Section, Atomic Bomb Disease Institute, Nagasaki University Graduate School of \\ Biomedical Sciences, Nagasaki, and ' Department of Respiratory Medicine, University of Occupational and \\ Environmental Health, Fukuoka, Japan
}

For editorial comment see p. 105

\section{Key Words}

Rapidly progressive interstitial pneumonia - Acute exacerbation • Polymyxin B direct hemoperfusion • Monocyte chemotactic protein $1 \cdot$ Arterial oxygen tension/inspiratory oxygen fraction ratio

\begin{abstract}
Background: Rapidly progressive interstitial pneumonia (IP), including acute exacerbation of IP, has a high mortality rate. Direct hemoperfusion with a polymyxin B-immobilized fiber column (PMX-DHP) was recently identified as an effective treatment for sepsis-associated acute respiratory distress syndrome. However, little is known about the effectiveness of PMX-DHP for rapidly progressive IP. Objectives: The present study investigates whether PMX-DHP is safe and effective against rapidly progressive IP. Methods: We retrospectively examined the effects of PMX-DHP in 33 consecutive patients with rapidly progressive IP who were resistant to steroid pulse therapy. Patients were hospitalized at Nagasaki University Hospital between 2006 and 2009. Results: Seventy-two hours after PMX-DHP, the arterial oxygen tension/inspiratory oxygen fraction ratio (median 127-153 mm $\mathrm{Hg}$ ) had significantly improved. One week after PMX-DHP, the arterial oxygen tension/inspiratory oxygen fraction ratio
\end{abstract}

\section{KARGER}

Fax +4161306 1234

E-Mail karger@karger.ch

www.karger.com
(C) 2010 S. Karger AG, Basel

$0025-7931 / 11 / 0812-0107 \$ 38.00 / 0$

Accessible online at:

www.karger.com/res (median 127-227 $\mathrm{mm} \mathrm{Hg}$ ), the alveolar-arterial difference of oxygen (median 371-177 mm Hg) and the number of positive criteria for systemic inflammatory response syndrome had significantly improved, despite the ineffectiveness of corticosteroid pulse therapy. The serum level of monocyte chemotactic protein 1 was significantly decreased immediately after PMX-DHP. Conclusions: PMX-DHP was safe and effective in improving oxygenation and systemic inflammatory response syndrome in patients with rapidly progressive IP. The beneficial effects of PMX-DHP may be at least partially due to the inhibition of monocyte activation.

Copyright $\odot 2010$ S. Karger AG, Basel

\section{Introduction}

Direct hemoperfusion with a polymyxin B-immobilized fiber column (PMX-DHP) has been used to treat sepsis by removing endotoxins produced by Gram-negative bacteria [1]. A recent multi-center randomized controlled trial confirmed that PMX-DHP is more effective than conventional therapy in patients with sepsis [2] and

\section{S.H. and H.I. contributed equally to this work.}


indicated that PMX-DHP might favorably affect endotoxin levels, arterial blood pressure, vasopressor requirement, the arterial oxygen tension $\left(\mathrm{PaO}_{2}\right)$ /inspiratory oxygen fraction $\left(\mathrm{FiO}_{2}\right)$ ratio $(\mathrm{P} / \mathrm{F})$ and mortality. Studies have also found that PMX-DHP is helpful for patients with complicated acute lung injury (ALI)/acute respiratory distress syndrome (ARDS), which is pathologically characterized by diffuse alveolar damage (DAD) [3-6]. DAD is also evident in some patients with rapidly progressive interstitial pneumonia (IP). The course of rapidly progressive IP is quick, the diagnostic modalities are suboptimal, and the outcomes are poor. In the present study, we define rapidly progressive IP as interstitial lung disease with acute to subacute respiratory failure, with bilateral infiltrative shadows on chest high-resolution computed tomography, and no known alternative causes of ALI (such as pneumonia, sepsis, trauma, toxic inhalation, blood infusion, acute pancreatitis, thromboembolism, or heart failure). Rapidly progressive IP includes idiopathic acute IP and IP with clinically amyopathic dermatomyositis [7-9]. Acute IP is a rapidly progressive condition of unknown cause that occurs in a previously healthy individual and produces the histologic findings of DAD [10]. Because of its acute presentation and histologic features similar to those of ARDS, acute IP is considered to be an idiopathic form of ARDS [10, 11]. In addition, patients with chronic IP sometimes rapidly deteriorate. This phenomenon is called 'acute exacerbation of IP' (AE-IP). Kondoh et al. [12] originally described AE-IP in patients with idiopathic pulmonary fibrosis. AE also occurs in idiopathic nonspecific IP, IP associated with connective tissue diseases, chronic hypersensitivity pneumonitis, and pneumoconiosis [13-16]. In this study, rapidly progressive IP also includes patients with AE-IP. Such patients are often resistant to intensive therapy, resulting in a fulminant and devastating course, with mortality rates ranging from 50 to $90 \%[7,14,17]$. Therefore, novel effective therapies for these rapidly progressive and fatal lung diseases are needed. A few small study reports indicate that PMX-DHP could be a promising treatment candidate [18-21]. The effects, safety and applicability of PMXDHP against rapidly progressive IP remain unknown. Furthermore, the mechanisms responsible for improved oxygenation after PMX-DHP have not been elucidated. To clarify the effectiveness and safety of PMX-DHP, we reviewed 33 consecutive patients with rapidly progressive IP. In addition, to elucidate the mechanism of effectiveness, we evaluated changes in serum chemokines associated with acute inflammation and lung injury, such as monocyte chemotactic protein 1 (MCP-1).

\section{Patients and Methods}

\section{Patients}

The Human Ethics Review Committees of Nagasaki University Hospital approved the study protocol. All participants or their families provided written, informed consent for all study procedures. Thirty-three consecutive patients with rapidly progressive IPs were enrolled in an open-label pilot trial of PMX-DHP at Nagasaki University Hospital between 2006 and 2009. Patients who met the following criteria were diagnosed with rapidly progressive IP: (1) development or unexplained worsening of dyspnea within 30 days; (2) high-resolution computed tomography with new bilateral ground-glass opacities and/or consolidation; (3) stable $\mathrm{P} / \mathrm{F}$ ratio $<300 \mathrm{~mm} \mathrm{Hg}$; and (4) absence of apparent infection, pneumothorax, pulmonary thromboembolism, heart failure or alternative causes of acute lung injury, such as trauma, blood infusion or toxic inhalation. Serological and urinary studies for the following pathogens and pathogen components were negative in all patients: endotoxin, Mycoplasma pneumoniae, Chlamydophila pneumoniae, Chlamydophila psittaci, cytomegalovirus antigenemia and $\beta$-D-glucan (for Pneumocystis jiroveci pneumonia), Legionella spp. and Streptococcus pneumoniae. Blood, sputum and urine cultures were also negative. Echocardiography demonstrated no evidence of heart failure in any of the patients.

The 33 study patients fulfilled our criteria (described above) for rapidly progressive IP; however, the patient group had varied etiologies. Effectiveness and prognosis could be influenced by underlying diseases and clinical course or treatment, especially mechanical ventilation. However, because of the small study population, the compartmentalization of diseases would make the statistical analysis difficult. Therefore, for our analysis, we separated the patients into 2 subgroups based on the presence or absence of idiopathic IP (IIP), which was diagnosed according to the classification system of the American Thoracic Society/European Respiratory Society [22]. The non-IIP group included patients with connective tissue disease-associated IP (underlying autoimmune diseases or vasculitis), drug-induced lung disease, pneumoconiosis and chronic hypersensitivity pneumonitis. Some patients had received bronchoalveolar lavage and surgical lung biopsy for the diagnosis of IP before the onset of rapidly progressive IP.

\section{Procedure}

We administered PMX-DHP to patients who were resistant to standard treatments for rapidly progressive IP, including highdose corticosteroid pulse therapy (methylprednisolone $1,000 \mathrm{mg}$ / day). The prednisolone dosage was tapered after high-dose corticosteroid pulse therapy, and immunosuppressants were also prescribed for some patients. Several reports have indicated that antioxidant therapy, such as $\mathrm{N}$-acetylcysteine [23-25] or anticoagulation therapy [26-28], is useful for ALI/ARDS; however, none of the study patients received antioxidant or anticoagulation therapy.

PMX-DHP (Toraymyxin, Toray Medical Co., Tokyo, Japan) was performed with conventional equipment and a circuit for hemodialysis. A double-lumen catheter was inserted into the femoral vein for venous access, and patients were directly hemoperfused at a flow rate of $80-100 \mathrm{ml} / \mathrm{min}$ for 3-24 h. Each patient received 1-6 treatments with PMX-DHP. Nafamostat mesylates (Torii Pharma Co. Ltd., Tokyo, Japan) were used as anticoagulants. We had no standard therapeutic criteria for the duration 
and number of PMX-DHP sessions; rather, we used the process of trial and error to determine the duration and number of PMXDHP sessions. The timing of administration, duration, number of cycles and time delay of each cycle were not unified and depended upon the assessment of the attending physician in each case. In a similar fashion, we had no standard ventilation strategy. The timing of intubation, duration, ventilation mode and ventilating parameters (including positive end-expiratory pressure level, tidal volume, airway pressure and respiratory rate) varied and depended on the assessment of the attending physicians.

Data Collection and Management

Clinical data were recorded at baseline (just prior to the first PMX-DHP session) and at $72 \mathrm{~h}$ and 1 week after the initial PMXDHP session. To evaluate the disease severity, we used the Acute Physiology and Chronic Health Evaluation (APACHE) II score (range 0-35; higher scores predict severe mortality) [29] and the Sequential Organ Failure Assessment (SOFA) score (range 0-24; lower scores indicate better organ function) [30]. The delta SOFA [31-33], which was calculated as the SOFA score at each time point minus the SOFA score at baseline, was used to determine the change in the degree of organ dysfunction after the 1st PMX-DHP session. The Glasgow Coma Scale of patients who underwent mechanical ventilation (MV) was assumed to be 3 points. The APACHE II score was assessed just prior to the first PMX-DHP. Furthermore, we assessed whether patients fulfilled the systemic inflammatory response syndrome (SIRS) criteria of the American College of Chest Physicians/Society of Critical Care Medicine consensus conference $[34,35]$. The $\mathrm{P} / \mathrm{F}$ ratio and alveolar-arterial oxygen difference $\left(\mathrm{A}-\mathrm{a} \mathrm{DO}_{2}\right)$ were approximated by the following expectation values of $\mathrm{FiO}_{2}$ in patients without $\mathrm{MV}$ : room air = 0.21 ; nasal cannula: $11 / \mathrm{min}=0.24,21 / \mathrm{min}=0.28,31 / \mathrm{min}=0.32$, $4 \mathrm{l} / \mathrm{min}=0.36,5 \mathrm{l} / \mathrm{min}=0.40 ;$ mask: $5 \mathrm{l} / \mathrm{min}=0.40,6 \mathrm{l} / \mathrm{min}=0.50$, $7 \mathrm{l} / \mathrm{min}=0.60$; reservoir mask: $6 \mathrm{l} / \mathrm{min}=0.60,7 \mathrm{l} / \mathrm{min}=0.70$, $8 \mathrm{l} / \mathrm{min}=0.80,9 \mathrm{l} / \mathrm{min}=0.90$, and $10 \mathrm{l} / \mathrm{min}=0.99 . \mathrm{PaO}_{2}$ and arterial carbon dioxide tension were measured by the analysis of arterial blood gas in all cases.

\section{Endpoints}

The primary endpoint was the change in the $\mathrm{P} / \mathrm{F}$ ratio from baseline (just prior to the 1st PMX-DHP session) to $72 \mathrm{~h}$ after the 1st PMX-DHP, which is the same primary endpoint as used in the EUPHAS trial [2]. The secondary endpoints included the change in the $\mathrm{P} / \mathrm{F}$ ratio from baseline to 1 week, changes in the $\mathrm{A}-\mathrm{a} \mathrm{DO}_{2}$, the number of positive SIRS criteria, the change in SOFA score from baseline to $72 \mathrm{~h}$ or 1 week after the 1st PMX-DHP, and the 30 - and 90-day mortality.

\section{Assessment of Safety}

To clarify the safety of PMX-DHP, we investigated body temperature, mean blood pressure, heart rate, respiratory rate, white blood cell and platelet count in all patients at baseline, $72 \mathrm{~h}$ and 1 week after the 1st PMX-DHP session.

\section{Measurement of Chemokines}

Blood samples were taken just before and after each PMXDHP treatment. The serum levels of MCP-1, interleukin (IL)-8, granulocyte colony-stimulating factor, growth-regulated peptide $\alpha$, epithelial neutrophil-activating peptide 78 and plasma levels of stromal cell-derived factor $1 \alpha$ were measured using ELISA kits.
The MCP-1 ELISA kit was from Bender MedSystems GmbH (Vienna, Austria), and all other kits were from R\&D Systems, Inc. (Minneapolis, Minn., USA). Blood samples were preserved by freezing and measured retrospectively. However, we could not collect blood samples in all cases, and some samples were not large enough to measure all chemokines. MCP-1 was measured in 51 cycles from 21 cases, and the other chemokines were measured in 20 cycles of 11 cases.

\section{Statistical Analysis}

Values are expressed as medians and interquartile ranges (IQRs) for continuous parameters. All statistical analyses were performed with SAS ${ }^{\circledR}$ (version 9.1, SAS Institute Inc., Cary, N.C., USA). We compared changes in the P/F ratio, A-a $\mathrm{DO}_{2}$, SIRS items, SOFA score, vital signs and other laboratory data between baseline and $72 \mathrm{~h}$ or 1 week after the first PMX-DHP session using the Wilcoxon test. We performed comparisons between the 2 subgroups, IIP and non-IIP, using a general linear model for repeated measures. We used the general linear model and NPAR1WAY in the SAS system for the calculations. Interactions between subgroups and time were also evaluated. Differences in mortality between the 2 subgroups were compared using the log-rank test. $p$ values $<0.05$ were considered statistically significant, and all tests were 2-tailed.

\section{Results}

\section{Clinical Features of Patients}

The clinical characteristics of all patients are shown in table 1. Thirty-three patients (18 men and 15 women) with a median age of 69 years (IQR 63-74) received a total of 73 cycles of PMX-DHP. Patients were classified into 2 subgroups, the IIP subgroup $(\mathrm{n}=17)$ and the non-IIP subgroup $(\mathrm{n}=16)$.

One patient (No. 22) was diagnosed with inflammatory myopathy with abundant macrophages based on the infiltration of CD68+ macrophages into the biopsied specimens, especially the fascia. Proximal skeletal muscle symptoms and signs, elevation of creatine kinase and myogenic changes in electromyography were present, but dermatomyositis-specific skin alterations were absent. One of the clinically amyopathic dermatomyositis patients (No. 23) has been described in a case report [20]. Drug-induced lung disease was suspected in 3 patients who received biapenem (No. 26), docetaxel (No. 27) or crude drug extract (Mitakesan-Fudogan ${ }^{\circledR}$; No. 28). Itraconazole-induced diffuse alveolar hemorrhage was suspected in patient No. 29, who has been described in a case report [36]. Eight patients were pathologically diagnosed by video-assisted surgical lung biopsy before the onset of rapidly progressive disease. Five patients had been diagnosed with clinical idiopathic pulmonary fibrosis without surgical lung biopsy according to the international 
Table 1. Clinical characteristics

\begin{tabular}{|c|c|c|c|c|c|c|c|c|c|c|}
\hline \multirow{2}{*}{$\begin{array}{l}\text { Patient } \\
\text { No. }\end{array}$} & \multirow{2}{*}{ Sex } & \multirow{2}{*}{$\begin{array}{l}\text { Age } \\
\text { years }\end{array}$} & \multirow[t]{2}{*}{ Subgroup } & \multirow[t]{2}{*}{ Diagnosis } & \multirow{2}{*}{$\begin{array}{l}\text { Duration of } \\
\text { underlying } \\
\text { disease } \\
\text { years }\end{array}$} & \multirow{2}{*}{$\begin{array}{l}\text { Histo- } \\
\text { patho- } \\
\text { logical } \\
\text { diagnosis }\end{array}$} & \multirow{2}{*}{$\begin{array}{l}\text { Previous } \\
\text { therapy }\end{array}$} & \multicolumn{3}{|l|}{ MV } \\
\hline & & & & & & & & $\begin{array}{l}\text { intuba- } \\
\text { tion }\end{array}$ & $\begin{array}{l}\text { commencing } \\
\text { from admis- } \\
\text { sion, days }\end{array}$ & $\begin{array}{l}\text { dura- } \\
\text { tion } \\
\text { days }\end{array}$ \\
\hline 1 & $\mathrm{~F}$ & 63 & IIP & IPF, AE & 2 & UIP & PSL+CPA & + & 3 & 45 \\
\hline 2 & $\mathrm{~F}$ & 61 & IIP & $\mathrm{IPF}, \mathrm{AE}$ & 8 & UIP & PSL+CPA & - & & \\
\hline 3 & $\mathrm{~F}$ & 81 & IIP & $\mathrm{IPF}, \mathrm{AE}$ & 7 & UIP & - & + & 1 & 7 \\
\hline 4 & $\mathrm{M}$ & 68 & IIP & $\mathrm{IPF}, \mathrm{AE}$ & 1 & UIP & - & - & & \\
\hline 5 & $\mathrm{M}$ & 69 & IIP & $\mathrm{IPF}, \mathrm{AE}$ & 2 & - & PSL+CyA & + & 7 & 20 \\
\hline 6 & $\mathrm{M}$ & 71 & IIP & IPF, AE & 2 & - & - & - & & \\
\hline 7 & $\mathrm{M}$ & 49 & IIP & $\mathrm{IPF}, \mathrm{AE}$ & 5 & - & NAC & - & & \\
\hline 8 & $\mathrm{M}$ & 56 & IIP & $\mathrm{IPF}, \mathrm{AE}$ & 4 months & - & pirfenidone & - & & \\
\hline 9 & $\mathrm{M}$ & 58 & IIP & $\mathrm{IPF}, \mathrm{AE}$ & 3 & - & PSL & + & 9 & 15 \\
\hline 10 & $\mathrm{M}$ & 67 & IIP & NSIP, AE & 3 & NSIP & - & + & 2 & 24 \\
\hline 11 & $\mathrm{M}$ & 67 & IIP & unclassified IP, AE & 1 & - & - & + & 2 & 4 \\
\hline 12 & $\mathrm{~F}$ & 75 & IIP & idiopathic AIP & - & - & - & NPPV & 1 & 11 \\
\hline 13 & M & 79 & IIP & idiopathic AIP & - & - & - & + & 2 & 57 \\
\hline 14 & $\mathrm{M}$ & 69 & IIP & idiopathic AIP & - & - & - & - & & \\
\hline 15 & $\mathrm{~F}$ & 65 & IIP & idiopathic AIP & - & - & - & + & 6 & 25 \\
\hline 16 & $\mathrm{~F}$ & 47 & IIP & idiopathic AIP & - & - & - & + & 0 & 14 \\
\hline 17 & $\mathrm{~F}$ & 81 & IIP & idiopathic AIP & - & - & - & + & 3 & 77 \\
\hline 18 & $\mathrm{~F}$ & 70 & non-IIP & $\mathrm{RA}, \mathrm{AE}$ & 18 & UIP & $\mathrm{PSL}+\mathrm{CyA}$ & NPPV & 2 & 3 \\
\hline 19 & $\mathrm{~F}$ & 74 & non-IIP & $\mathrm{RA}, \mathrm{DM}, \mathrm{SjS}, \mathrm{AE}$ & 15 & UIP & PSL+mizoribine & + & 3 & 4 \\
\hline 20 & $\mathrm{~F}$ & 72 & non-IIP & primary $\mathrm{SjS}, \mathrm{AE}$ & 3 & - & - & + & 3 & 5 \\
\hline 21 & M & 74 & non-IIP & systemic vasculitis, $\mathrm{AE}$ & 1 & - & - & - & & \\
\hline 22 & $\mathrm{~F}$ & 46 & non-IIP & IMAM, ARS & - & - & - & - & & \\
\hline 23 & M & 70 & non-IIP & CADM & - & - & - & + & 2 & 8 \\
\hline 24 & $\mathrm{~F}$ & 60 & non-IIP & CADM & - & - & - & - & & \\
\hline 25 & $\mathrm{~F}$ & 69 & non-IIP & CADM & - & - & - & - & & \\
\hline 26 & $\mathrm{M}$ & 85 & non-IIP & drug-induced IP & - & - & - & + & 3 & 82 \\
\hline 27 & $\mathrm{~F}$ & 69 & non-IIP & drug-induced IP & - & - & - & NPPV & 11 & 3 \\
\hline 28 & $\mathrm{M}$ & 82 & non-IIP & drug-induced IP & - & - & - & + & 2 & 21 \\
\hline 29 & $\mathrm{M}$ & 53 & non-IIP & drug-induced alveolar hemorrhage & - & - & - & + & 0 & 5 \\
\hline 30 & $\mathrm{~F}$ & 75 & non-IIP & asbestosis, $\mathrm{AE}$ & 10 & - & PSL & - & & \\
\hline 31 & $\mathrm{M}$ & 82 & non-IIP & asbestosis, AE & 30 & - & - & - & & \\
\hline 32 & M & 69 & non-IIP & asbestosis, $\mathrm{AE}$ & 2 & - & - & + & 4 & 15 \\
\hline 33 & M & 65 & non-IIP & chronic $\mathrm{HP}, \mathrm{AE}$ & 2 & NSIP & - & - & & \\
\hline
\end{tabular}

Histopathological diagnosis was revealed by surgical lung biopsy before the onset of rapidly progressive IP. All patients were treated with oral or intravenous corticosteroids after high-dose corticosteroid pulse therapy.

CyA = Cyclosporin A; IPF = idiopathic pulmonary fibrosis; UIP = usually interstitial pneumonia; $\mathrm{PSL}=$ prednisolone; $\mathrm{CPA}=$ cyclophosphamide; NAC = inhalation of $\mathrm{N}$-acetylcysteine; NSIP = non-specific interstitial pneumonia; $\mathrm{AIP}=$ acute interstitial pneumonia; NPPV $=$ non-invasive pos- itive airway pressure ventilation; $\mathrm{RA}=$ rheumatoid arthritis; $\mathrm{DM}=$ dermatomyositis; $\mathrm{SjS}=$ Sjögren syndrome; IMAM = inflammatory myopathy with abundant macrophages; ARS = anti-aminoacyl tRNA synthetase syndrome; CADM = clinically amyopathic dermatomyositis; $\mathrm{TA}=$ tacrolimus; $\mathrm{HP}=$ hypersensitivity pneumonia.

${ }^{1}$ Tacrolimus, cyclophosphamide, leukocytapheresis and plasmapheresis (case No. 22). consensus statement of the American Thoracic Society/ European Respiratory Society [22]. Six patients received corticosteroid therapy before onset; four of these patients underwent immunosuppressive therapy with cyclophosphamides $(n=2)$, cyclosporin $(n=1)$ or mizoribine $(n=$
1). One patient received inhalation therapy with $\mathrm{N}$-acetylcysteine, and 1 patient pirfenidone. PMX-DHP treatment was commenced after a median of 5 days (IQR 3.06.0) from admission and 3 days (IQR $2-5$ ) from the start of corticosteroid pulse therapy. The median number of 


\begin{tabular}{|c|c|c|c|c|c|c|c|c|}
\hline \multicolumn{5}{|l|}{ PMX-DHP } & \multicolumn{2}{|c|}{ Treatment } & \multirow[t]{2}{*}{ Outcome } & \multirow{2}{*}{$\begin{array}{l}\text { Survival } \\
\text { (from 1st } \\
\text { PMX-DHP) } \\
\text { days }\end{array}$} \\
\hline $\begin{array}{l}\text { commencing } \\
\text { from admission } \\
\text { days }\end{array}$ & $\begin{array}{l}\text { starting from } \\
\text { steroid pulse } \\
\text { therapy, days }\end{array}$ & cycles & $\begin{array}{l}\text { duration } \\
\mathrm{h}\end{array}$ & $\begin{array}{l}\text { time delay } \\
\text { between each } \\
\text { cycle, days }\end{array}$ & СуA & others & & \\
\hline 7 & 4 & 3 & 4 & 2,5 & + & & dead & 41 \\
\hline 5 & 5 & 2 & 4 & 1 & + & & alive & \\
\hline 2 & 2 & 2 & 3 & 1 & + & & dead & 13 \\
\hline 4 & 4 & 2 & 8.5 & 1 & + & & alive & \\
\hline 6 & 6 & 4 & 4 & $2,2,2$ & + & & dead & 22 \\
\hline 6 & 0 & 6 & 4 & $2,4,1,8,1$ & + & & dead & 25 \\
\hline 4 & 4 & 3 & 6 & 2 & + & & dead & 75 \\
\hline 6 & 6 & 2 & 6 & 2 & + & & alive & \\
\hline 9 & 1 & 2 & 19 & 2 & - & & dead & 15 \\
\hline 5 & 4 & 2 & 4 & 1 & + & & alive & \\
\hline 3 & 3 & 1 & 4 & - & - & & alive & \\
\hline 1 & 1 & 4 & 4 & $3,3,4$ & + & CPA & dead & 11 \\
\hline 2 & 2 & 4 & 4 & $2,6,6$ & + & & dead & 57 \\
\hline 3 & 2 & 2 & 6 & 1 & + & & alive & \\
\hline 6 & 4 & 2 & 4 & 2 & + & & dead & 25 \\
\hline 9 & 9 & 2 & 6 & 1 & - & & dead & 14 \\
\hline 3 & 3 & 1 & 18 & - & + & & dead & 79 \\
\hline 2 & 2 & 2 & 4 & 2 & + & & alive & \\
\hline 4 & 2 & 1 & 6 & - & + & & dead & 20 \\
\hline 3 & 2 & 2 & 3 & 1 & - & & alive & \\
\hline 4 & 4 & 2 & 6 & 1 & - & CPA & alive & \\
\hline 2 & 1 & 1 & 4 & - & - & $-^{1}$ & alive & \\
\hline 7 & 5 & 2 & 3 & 1 & + & & alive & \\
\hline 17 & 16 & 2 & 3 & 1 & + & & alive & \\
\hline 18 & 11 & 3 & 4 & 5,15 & + & $\mathrm{CPA}, \mathrm{TA}$ & dead & 24 \\
\hline 6 & 3 & 2 & 4 & 1 & + & & alive & \\
\hline 12 & 12 & 2 & 6 & 2 & - & & dead & 7 \\
\hline 6 & 5 & 2 & 4 & 1 & + & & dead & 58 \\
\hline 2 & 2 & 1 & 24 & - & - & & alive & \\
\hline 2 & 2 & 2 & 4 & 2 & - & & dead & 21 \\
\hline 8 & 8 & 2 & 4 & 2 & + & & alive & \\
\hline 3 & 3 & 1 & 6 & - & - & & dead & 16 \\
\hline 5 & 2 & 2 & 4 & 1 & + & & alive & \\
\hline
\end{tabular}

cycles was 2 (IQR 2-2), and the median duration was $4 \mathrm{~h}$ (IQR 4-6). Twenty patients received MV (17 intubated and 3 noninvasive positive-airway pressure ventilations) by 1 week after the initial PMX-DHP treatment. The ventilation was commenced at a median of 2.5 days (IQR
2.0-3.3) after admission, and the median duration was 14.5 days (IQR 5.0-24.3). Of the 17 patients who died, 13 underwent mechanical ventilation, and 5 of them had been weaned from it once. However, they eventually died from the exacerbation of respiratory failure or infection 
Table 2. Clinical course of laboratory data and vital signs

\begin{tabular}{|c|c|c|c|c|c|c|c|c|c|c|c|}
\hline \multirow[t]{2}{*}{ Value } & \multicolumn{3}{|l|}{ Baseline } & \multicolumn{4}{|l|}{$72 \mathrm{~h}$} & \multicolumn{4}{|l|}{1 week } \\
\hline & median & IQR & $\mathrm{n}$ & median & IQR & $\mathrm{n}$ & $\mathrm{p}$ value & median & IQR & $\mathrm{n}$ & $\mathrm{p}$ value \\
\hline $\mathrm{P} / \mathrm{F}$ ratio, $\mathrm{mm} \mathrm{Hg}$ & 127.0 & $91.1-150.9$ & 33 & 152.8 & $116.5-274.4$ & 33 & 0.02 & 226.7 & $138.2-307.6$ & 33 & 0.0004 \\
\hline $\mathrm{A}-\mathrm{a} \mathrm{DO}_{2}, \mathrm{~mm} \mathrm{Hg}$ & 370.6 & $173.2-430.2$ & 33 & 278.7 & $138.5-418.7$ & 33 & NS & 177.2 & $61.1-299.2$ & 33 & 0.0014 \\
\hline Positive SIRS criteria & 2 & $1-2$ & 30 & 1 & $1-2$ & 30 & 0.06 & 1 & $0-2$ & 30 & 0.04 \\
\hline SOFA score & 4 & $3-8.5$ & 28 & 5 & $3-9$ & 27 & NS & 4 & $2-8$ & 27 & NS \\
\hline Body temperature, ${ }^{\circ} \mathrm{C}$ & 36.7 & $36.4-37.0$ & 31 & 36.6 & $36.5-36.9$ & 31 & NS & 36.6 & $36.4-36.8$ & 31 & NS \\
\hline Mean blood pressure, $\mathrm{mm} \mathrm{Hg}$ & 90 & $79.3-100.7$ & 31 & 89 & $78.7-96.0$ & 30 & NS & 89 & $77.3-96.7$ & 30 & NS \\
\hline Heart rate, beats/min & 84 & $71-100$ & 31 & 78 & $60-86$ & 31 & 0.09 & 76 & $60-88$ & 31 & NS \\
\hline Respiratory rate, beats/min & 24 & $20-30$ & 31 & 20 & $20-28$ & 31 & 0.03 & 22 & $20-30$ & 31 & 0.08 \\
\hline White blood cell, $10^{3} / \mu \mathrm{l}$ & 12,300 & $9,900-16,900$ & 32 & 9,400 & $7,600-12,900$ & 30 & 0.01 & 10,250 & $9,000-15,700$ & 30 & NS \\
\hline Platelet count, $10^{4} / \mu \mathrm{l}$ & 18.7 & $12.8-25.0$ & 30 & 14.0 & $10.1-19.0$ & 30 & 0.05 & 17.3 & $11.4-24.0$ & 30 & NS \\
\hline
\end{tabular}

Comparisons between baseline and $72 \mathrm{~h}$ or 1 week were performed with the Wilcoxon test. Values are expressed as medians and IQRs (25-75\%). NS = Not significant.

Table 3. Subgroup comparisons (IIP vs. non-IIP)

\begin{tabular}{llll}
\hline & p value & & \\
\cline { 2 - 4 } & $\begin{array}{l}\text { between sub- } \\
\text { jects (subgroup) }\end{array}$ & $\begin{array}{l}\text { within sub- } \\
\text { jects (time) }\end{array}$ & $\begin{array}{l}\text { subject-time } \\
\text { interaction }\end{array}$ \\
\hline P/F ratio & 0.03 & $<0.0001$ & 0.07 \\
A-a DO 2 & 0.09 & 0.0001 & NS \\
SIRS & NS & 0.002 & NS \\
SOFA & NS & NS & NS \\
\hline
\end{tabular}

Thirty-three patients were divided into 2 subgroups: IIP and non-IIP. The comparisons between the 2 subgroups were calculated by a general linear model for repeated measures in the SAS system. NS = Not significant.

including $P$. jiroveci pneumonia, cytomegalovirus pneumonia and multidrug-resistant Pseudomonas aeruginosa pneumonia. Pathological assessments of 3 patients (No. 1,3 and 12) at autopsy confirmed that they had DAD.

\section{Primary Endpoints}

The P/F ratio among the entire patient group significantly improved from baseline to $72 \mathrm{~h}$ after the 1st PMXDHP session (table 2; fig. 1a). However, improvement in the $\mathrm{P} / \mathrm{F}$ ratio at $72 \mathrm{~h}$ among patients in each subgroup was not statistically significant (fig. 1b).

\section{Secondary Endpoints}

The $\mathrm{P} / \mathrm{F}$ ratio and $\mathrm{A}-\mathrm{a} \mathrm{DO}_{2}$ among the entire patient group significantly improved from baseline to 1 week af- ter the 1st PMX-DHP session (table 2; fig. 1a, Wilcoxon test). The number of patients who fulfilled SIRS criteria decreased from 16 of 31 (at baseline) to 11 of 30 (at $72 \mathrm{~h}$ ) and to 10 of 30 (at 1 week); however, these changes were not statistically significant as determined by the $\chi^{2}$ test. On the other hand, the number of positive SIRS criteria was significantly decreased 1 week after treatment (table 2). The SOFA score showed no significance overall (table 2). A between-subgroup comparison performed with the general linear model for repeated measures revealed that the $\mathrm{P} / \mathrm{F}$ ratio showed statistical significance (table 3). But none of the items showed a significant interaction between subgroup and time.

Thirty-day mortality was $36.4 \%$ (12 of 33 patients), and 90 -day mortality was $51.6 \%$ (17 of 33 patients). The median survival duration was 27 days (IQR 19-48) from admission and 22 days (IQR 15-41) from the 1st PMXDHP treatment. In subgroup comparisons performed with the log-rank test, the 30- and 90-day mortality was 41.2 (7 of 17) and $64.7 \%$ (11 of 17) for the IIP subgroup and 31.3 (5 of 16 ) and $37.5 \%$ (6 of 16) for the non-IIP subgroup, respectively $(\mathrm{p}=0.18)$.

\section{Safety and Adverse Reactions}

To clarify the safety of PMX-DHP, we investigated the clinical course of the vital signs and laboratory data (table 2). Patient vital signs did not deteriorate during PMXDHP treatment, and no patient required additive vasopressor. White blood cell counts significantly decreased $72 \mathrm{~h}$ after the 1st PMX-DHP session, but they remained increased 1 week after the 1st PMX-DHP session. Platelet 

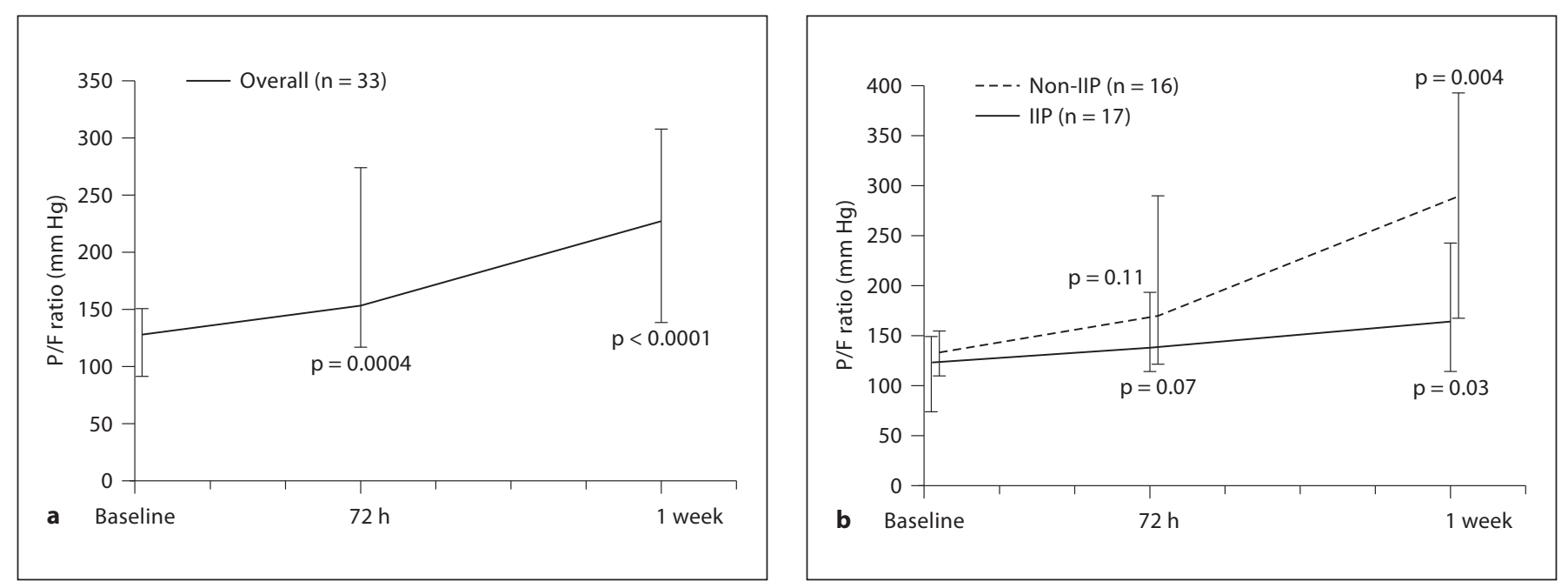

Fig. 1. Clinical course of $\mathrm{P} / \mathrm{F}$ ratio. The statistical analysis was performed with the Wilcoxon test. The $\mathrm{p}$ values indicate the comparisons with baseline values. Values are expressed as medians and IQRs (25-75\%). a Overall. b Subgroup comparison.

Table 4. Changes in chemokines

\begin{tabular}{|c|c|c|c|c|c|c|}
\hline \multirow[t]{2}{*}{ Chemokines } & \multicolumn{2}{|c|}{ Pre-PMX-DHP } & \multicolumn{2}{|c|}{ Post-PMX-DHP } & \multirow[t]{2}{*}{ Sessions } & \multirow[t]{2}{*}{$\mathrm{p}$ value } \\
\hline & median & IQR & median & IQR & & \\
\hline MCP-1 & 637 & $494-1,193$ & 460 & $375-893$ & 51 & $<0.001$ \\
\hline IL-8 & 38.8 & $30.4-50.7$ & 40.5 & $32.1-57.3$ & 20 & NS \\
\hline $\mathrm{GRO} \alpha$ & 64.5 & $52.0-90.8$ & 56.6 & $46.9-68.9$ & 20 & 0.08 \\
\hline ENA-78 & 289 & 233-542 & 290 & $158-481$ & 20 & NS \\
\hline SDF- $1 \alpha$ & 2,314 & $2,028-2,579$ & 2,374 & $2,002-2,575$ & 20 & NS \\
\hline
\end{tabular}

Statistical analysis was performed with the Wilcoxon's signed rank test. Values are expressed as medians and IQRs. NS = Not significant; GRO $\alpha=$ growth-regulated peptide $\alpha$; ENA-78 = epithelial neutrophil-activating peptide 78; SDF-1 $\alpha=$ stromal cell-derived factor $1 \alpha$.

counts also significantly decreased at $72 \mathrm{~h}$ but recovered 1 week after the 1st PMX-DHP session. None of the patients showed a tendency to bleed or required a blood transfusion during PMX-DHP. The serum levels of C-reactive protein obviously decreased during the clinical course. However, the serum levels of lactate dehydrogenase, blood urea nitrogen, creatinine, sodium and potassium were not affected by PMX-DHP (data not shown).

\section{Chemokines}

Serum levels of MCP-1 were significantly decreased immediately after PMX-DHP as compared with baseline levels ( $p<0.001$ ) (table 4). The levels of MCP-1 decreased significantly in both the survivor group (median 590-
$399 ; \mathrm{p}=0.003$ ) and the non-survivor group (median 642$466 ; \mathrm{p}=0.02$ ), and no significant difference was observed between the 2 groups. Serum levels of IL-8, growth-regulated peptide $\alpha$, epithelial neutrophil-activating peptide 78 and stromal cell-derived factor $1 \alpha$ were not significantly affected.

\section{Discussion}

Our results indicate that PMX-DHP offers promise as a safe and effective therapy for rapidly progressive IP of different etiologies that is resistant to initial corticosteroid pulse therapy. This study is the first retrospective 
investigation of more than 30 patients with rapidly progressive IP. We found that PMX-DHP improved oxygenation at $72 \mathrm{~h}$ and SIRS criteria at 1 week after the 1 st PMXDHP session. The improved oxygenation occurred in both the IIP subgroup and the non-IIP subgroup. Also, the serum levels of MCP-1 were decreased just after PMXDHP; this decrease may precede the enhancement of oxygenation.

Rapidly progressive IP is a very complex and severe disease, and it requires intensive therapy. The major finding in the present study is that PMX-DHP rapidly improved oxygenation in patients whose oxygenation had deteriorated despite initial corticosteroid pulse therapy. Of the 17 patients who died, 13 patients underwent mechanical ventilation. Five ventilated patients were weaned from the ventilation at one point. Our findings are consistent with other reports that have described the effectiveness of PMX-DHP for patients with AE-IP [18, 19, 21]. In addition to our assessment of oxygenation, we also assessed the systemic effect of PMX-DHP on rapidly progressive IP. PMX-DHP has been reported to affect endotoxin levels, arterial blood pressure, vasopressor requirements and the P/F ratio. These reports indicated that PMX-DHP has a beneficial effect on rapidly progressive IP by not only improving oxygenation but also by regulating the patient's systemic status. In the present study, the number of patients who fulfilled SIRS criteria decreased after PMX-DHP. Likewise, the number of positive SIRS criteria was significantly decreased 1 week after the 1st PMX-DHP session. SIRS, which is a systemic host response to infection and other forms of tissue injury, reflects changes in thermoregulation, the emergence of cardiovascular and respiratory instability, and alterations in white blood cell count $[34,35]$. SIRS progresses to ALI/ ARDS, whereas rapidly progressive IP also progresses to SIRS and multiple organ dysfunctions. Assessment of SIRS criteria in patients with rapidly progressive IP could identify other benefits of PMX-DHP. A recent randomized controlled study showed that PMX-DHP improved SOFA scores and the mortality rate of patients with sepsis [2]. However, in the present study, the SOFA score was not affected by PMX-DHP. Other scoring systems could be useful to assess patients with IP; for example, the RIFLE score predicts the outcome of ARDS patients who undergo open lung biopsy [37]. The mortality rates for patients with rapidly progressive IP in 3 recent reports [18, $19,21]$ were $33.3,50$ and $60 \%$, respectively. The 30 -day mortality rate in the present study was $36.3 \%$, and the 90 day mortality rate was $51.6 \%$. Rapidly progressive IP has an extremely poor prognosis, and the initial treatment at the acute stage is important. For these reasons, we have emphasized the short-term effects of PMX-DHP and included 30- and 90-day mortality as secondary endpoints. Although the length of the final observation period varied from 1 to 4 years because of the retrospective nature of the study, the 90-day morality rate was the same as the mortality rate at the final observation period. Re-exacerbation of respiratory failure or infection should be prevented during the clinical course to decrease the final mortality rate. Because this study is a retrospective cohort study, whether or not PMX-DHP can reduce mortality remains unknown. Although the transient improvement in oxygenation did not ensure a good prognosis, the improved oxygenation could preserve lung tissue from oxygen toxicity, reduce the duration of mechanical ventilation and provide an opportunity for other intensive therapies to work.

The patients with rapidly progressive IP in the present study formed a heterogeneous population with different underlying diseases and therapies other than PMX-DHP. To discover the population that responded to PMX-DHP, we divided the patients into 2 subgroups (IIP or non-IIP) based on the underlying IP. The oxygenation and SIRS criteria were improved by PMX-DHP in both subgroups. Although the P/F ratio at 1 week after the 1st PMX-DHP session in the non-IIP group was significantly higher than in the IIP group, no significant interaction between subgroup and time was observed. The 30- and 90-day mortality was not significantly different between the 2 subgroups.

When we attempt new treatment methods, it is important to assure that the methods are safe, especially for severe cases. In the present study, the patients' vital signs were stabilized, and there were no adverse reactions or changes in laboratory data, except for mild thrombocytopenia. Furthermore, there have been no reports that PMX-DHP reduces the in vivo efficiency of treatment with steroids or immunosuppressants. Thus, PMX-DHP can be safely administered to patients with rapidly progressive IP.

The mechanisms by which PMX-DHP improves oxygenation in rapidly progressive IP remain unclear. Here, we found that the serum levels of MCP-1 after PMX-DHP were significantly decreased as compared with the levels before PMX-DHP treatment. MCP-1 is produced by a variety of cells including monocytes. It belongs to the CC subgroup ( $\beta$ subfamily) of the chemokine superfamily [38] that plays a critical role in the recruitment and activation of monocytes during acute inflammation [39]. On the other hand, serum levels of IL-8, growth-regulated 
peptide $\alpha$, stromal cell-derived factor $1 \alpha$ and epithelial neutrophil-activating peptide 78 were not affected. These mediators belong to the CXC family ( $\alpha$ subfamily) that selectively attracts neutrophils. The MCP-1 levels in bronchoalveolar lavage fluid and sera in patients with idiopathic pulmonary fibrosis and other types of IP are increased [40-42]; likewise, increased levels of CXC chemokines are associated with pathological conditions in IP [43-45]. The blood levels of some inflammatory chemokines, e.g. metalloproteinase 9, tissue inhibitor of metalloproteinase 1 [4], neutrophil elastase, IL-8 [46] and IL-18 [47], are immediately decreased in ARDS patients after PMX-DHP. Seo et al. [18] have reported that IL-6, IL- 8 and plasminogen activator inhibitor 1 are decreased in patients with rapidly progressive IP who responded to PMX-DHP. Noma et al. [19] have reported that high mobility group box 1, MCP-1, IL- 6 and IL- 8 are reduced $72 \mathrm{~h}$ after PMX-DHP. Our results indicate that MCP-1 itself or MCP-1-producing cells including monocytes may be absorbed by PMX-DHP. Kushi et al. [48] have shown that PMX-DHP decreases macrophage and monocyte activity, and Nishibori et al. [49] have used immunocytochemical and microscopic techniques to demonstrate that PMX-DHP binds to monocytes. Although it is unclear whether the reduction of such chemokines has direct or indirect effects, the decreasing MCP-1 levels might partially explain the benefits of PMX-DHP. The measurement of chemokines along with clinical courses may provide new insights, and further studies are required to elucidate the precise mechanisms responsible for the beneficial effects of PMX-DHP.
The present study has a number of limitations. The study cohort was small, the design was retrospective, and the pathological findings were unclear in most patients. In addition, the etiologies, the underlying diseases and treatments, the number and durations of PMX-DHP treatments, and the time lag between each PMX-DHP treatment, the combination therapies and the administration and setting of MV were highly varied.

In the present study, we found that PMX-DHP safely improved oxygenation and reduced the severity of SIRS in patients with rapidly progressive IP. Rapidly progressive IP, including AE-IP, can be lethal, and therapeutic criteria have not been established. Therefore, PMX-DHP has therapeutic potential for such patients. Further prospective controlled studies with large numbers of patients and a placebo group are required to address the limitations of the present study and to identify a suitable method for PMX-DHP administration to treat rapidly progressive IP.

\section{Acknowledgements}

A portion of the PMX-DHP treatments was financed by the national treasury of Japan. This study was partly supported by a grant to the Diffuse Lung Diseases Research Group from the Ministry of Health, Labour and Welfare, Japan. We are grateful to Dr. Takashi Harada for PMX-DHP administration, to Drs Towako Nagata, Keiko Hisatomi, Hanako Fujita, Sumako Yoshioka, Misato Amenomori, Atsuko Hara, Shota Nakashima and Tatsuhiko Harada for data acquisition, and to Atsushi Yokoyama for the technical support in the measurement of chemokines.

\section{References}

1 Shoji H: Extracorporeal endotoxin removal for the treatment of sepsis: endotoxin adsorption cartridge (Toraymyxin). Ther Apher Dial 2003;7:108-114.

-2 Cruz DN, Antonelli M, Fumagalli R, Foltran F, Brienza N, Donati A, Malcangi V, Petrini F, Volta G, Bobbio Pallavicini FM, Rottoli F, Giunta F, Ronco C: Early use of polymyxin B hemoperfusion in abdominal septic shock: the EUPHAS randomized controlled trial. JAMA 2009;301:2445-2452.

- 3 Tsushima K, Kubo K, Koizumi T, Yamamoto H, Fujimoto K, Hora K, Kan-Nou Y: Direct hemoperfusion using a polymyxin B-immobilized column improves acute respiratory distress syndrome. J Clin Apher 2002;17:97102.
-4 Nakamura T, Kawagoe Y, Matsuda T, Shoji H, Ueda Y, Tamura N, Ebihara I, Koide H: Effect of polymyxin B-immobilized fiber on blood metalloproteinase- 9 and tissue inhibitor of metalloproteinase-1 levels in acute respiratory distress syndrome patients. Blood Purif 2004;22:256-260.

-5 Tsushima K, Kubo K, Yoshikawa S, Koizumi T, Yasuo M, Furuya S, Hora K: Effects of PMX-DHP treatment for patients with directly induced acute respiratory distress syndrome. Ther Apher Dial 2007;11:138-145.

-6 Cruz DN, Perazella MA, Bellomo R, de Cal M, Polanco N, Corradi V, Lentini P, Nalesso F, Ueno T, Ranieri VM, Ronco C: Effectiveness of polymyxin B-immobilized fiber column in sepsis: a systematic review. Crit Care 2007;11:R47.
7 Swigris JJ, Brown KK: Acute interstitial pneumonia and acute exacerbations of idiopathic pulmonary fibrosis. Semin Respir Crit Care Med 2006;27:659-667.

-8 Sakamoto N, Mukae H, Fujii T, Yoshioka S, Kakugawa T, Yamaguchi H, Hayashi T, Kohno S: Nonspecific interstitial pneumonia with poor prognosis associated with amyopathic dermatomyositis. Intern Med 2004; 43:838-842.

9 Suda T, Fujisawa T, Enomoto N, Nakamura Y, Inui N, Naito T, Hashimoto D, Sato J, Toyoshima $\mathrm{M}$, Hashizume $\mathrm{H}$, Chida $\mathrm{K}$ : Interstitial lung diseases associated with amyopathic dermatomyositis. Eur Respir J 2006; 28:1005-1012. 


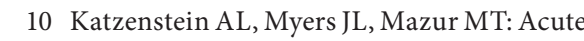
interstitial pneumonia. A clinicopathologic, ultrastructural, and cell kinetic study. Am J Surg Pathol 1986;10:256-267.

$\checkmark 11$ Olson J, Colby TV, Elliott CG: HammanRich syndrome revisited. Mayo Clin Proc 1990;65:1538-1548.

- 12 Kondoh Y, Taniguchi H, Kawabata Y, Yokoi T, Suzuki K, Takagi K: Acute exacerbation in idiopathic pulmonary fibrosis. Analysis of clinical and pathologic findings in three cases. Chest 1993;103:1808-1812.

13 Kondoh Y, Taniguchi H, Kitaichi M, Yokoi T, Johkoh T, Oishi T, Kimura T, Nishiyama O, Kato K, du Bois RM: Acute exacerbation of interstitial pneumonia following surgical lung biopsy. Respir Med 2006;100:17531759.

- 14 Suda T, Kaida Y, Nakamura Y, Enomoto N, Fujisawa T, Imokawa S, Hashizume H, Naito T, Hashimoto D, Takehara Y, Inui N, Nakamura H, Colby TV, Chida K: Acute exacerbation of interstitial pneumonia associated with collagen vascular diseases. Respir Med 2009; 103:846-853.

-15 Inase N, Sakashita H, Ohtani Y, Sogou Y, Sumi Y, Umino T, Usui Y, Yoshizawa Y: Chronic bird fancier's lung presenting with acute exacerbation due to use of a feather duvet. Intern Med 2004;43:835-837.

16 Yamamoto S: Histopathological features of pulmonary asbestosis with particular emphasis on the comparison with those of usual interstitial pneumonia. Osaka City Med J 1997;43:225-242.

$\checkmark 17$ Agarwal R, Jindal SK: Acute exacerbation of idiopathic pulmonary fibrosis: a systematic review. Eur J Intern Med 2008;19:227-235.

- 18 Seo Y, Abe S, Kurahara M, Okada D, Saito Y, Usuki J, Azuma A, Koizumi K, Kudoh S: Beneficial effect of polymyxin B-immobilized fiber column (PMX) hemoperfusion treatment on acute exacerbation of idiopathic pulmonary fibrosis. Intern Med 2006;45: 1033-1038.

-19 Noma S, Matsuyama W, Mitsuyama H, Suetsugu T, Koreeda Y, Mizuno K, Higashimoto I, Kakihana Y, Hashiguchi T, Maruyama I, Osame M, Arimura K: Two cases of acute exacerbation of interstitial pneumonia treated with polymyxin B-immobilized fiber column hemoperfusion treatment. Intern Med 2007;46:1447-1454.

-20 Kakugawa T, Mukae H, Saito M, Ishii K, Ishimoto H, Sakamoto N, Takazono T, Fukuda Y, Ooe N, Kohno S: Rapidly progressive interstitial pneumonia associated with clinically amyopathic dermatomyositis successfully treated with polymyxin B-immobilized fiber column hemoperfusion. Intern Med 2008:47:785-790.

21 Enomoto N, Suda T, Uto T, Kato M, Kaida Y, Ozawa Y, Miyazaki H, Kuroishi S, Hashimoto D, Naito T, Fujisawa T, Matsui T, Inui N, Nakamura Y, Sato J, Mizuguchi T, Kato A, Chida K: Possible therapeutic effect of direct haemoperfusion with a polymyxin B immo- bilized fibre column (PMX-DHP) on pulmonary oxygenation in acute exacerbations of interstitial pneumonia. Respirology 2008; 13 : 452-460.

22 American Thoracic Society (ATS)/European Respiratory Society (ERS) International Multidisciplinary Consensus Classification of the Idiopathic Interstitial Pneumonias. Am J Respir Crit Care Med 2002;165:277304.

23 Suter PM, Domenighetti G, Schaller MD, Laverriere MC, Ritz R, Perret C: N-acetylcysteine enhances recovery from acute lung injury in man. A randomized, double-blind, placebo-controlled clinical study. Chest 1994;105:190-194.

24 Bernard GR, Wheeler AP, Arons MM, Morris PE, Paz HL, Russell JA, Wright PE: A trial of antioxidants $\mathrm{N}$-acetylcysteine and procysteine in ARDS. The Antioxidant in ARDS Study Group. Chest 1997;112:164-172.

25 Domenighetti G, Suter PM, Schaller MD, Ritz R, Perret C: Treatment with N-acetylcysteine during acute respiratory distress syndrome: a randomized, double-blind, placebo-controlled clinical study. J Crit Care 1997;12:177-182.

26 Ware LB, Bastarache JA, Wang L: Coagulation and fibrinolysis in human acute lung injury - new therapeutic targets? Keio J Med 2005;54:142-149.

27 Chambers RC: Procoagulant signalling mechanisms in lung inflammation and fibrosis: novel opportunities for pharmacological intervention? Br J Pharmacol 2008; 153(suppl 1):S367-S378.

28 Hofstra JJ, Juffermans NP, Schultz MJ, Zweers MM: Pulmonary coagulopathy as a new target in lung injury - a review of available pre-clinical models. Curr Med Chem 2008;15:588-595.

29 Knaus WA, Draper EA, Wagner DP, Zimmerman JE: Apache II: a severity of disease classification system. Crit Care Med 1985;13: 818-829.

30 Vincent JL, de Mendonca A, Cantraine F, Moreno R, Takala J, Suter PM, Sprung CL, Colardyn F, Blecher S: Use of the SOFA score to assess the incidence of organ dysfunction/ failure in intensive care units: results of a multicenter, prospective study. Working group on 'sepsis-related problems' of the European Society of Intensive Care Medicine. Crit Care Med 1998;26:1793-1800.

- 31 Moreno R, Vincent JL, Matos R, Mendonca A, Cantraine F, Thijs L, Takala J, Sprung C, Antonelli M, Bruining $\mathrm{H}$, Willatts S: The use of maximum SOFA score to quantify organ dysfunction/failure in intensive care. Results of a prospective, multicentre study. Working group on sepsis related problems of the ESICM. Intensive Care Med 1999;25:686696.

32 Ferreira FL, Bota DP, Bross A, Melot C, Vincent JL: Serial evaluation of the SOFA score to predict outcome in critically ill patients. JAMA 2001;286:1754-1758.
33 Jones AE, Trzeciak S, Kline JA: The sequential organ failure assessment score for predicting outcome in patients with severe sepsis and evidence of hypoperfusion at the time of emergency department presentation. Crit Care Med 2009;37:1649-1654.

34 Levy MM, Fink MP, Marshall JC, Abraham E, Angus D, Cook D, Cohen J, Opal SM, Vincent JL, Ramsay G, International Sepsis Definitions Conference: 2001 SCCM/ESICM/ ACCP/ATS/SIS International Sepsis Definitions Conference. Intensive Care Med 2003. 29:530-538.

35 American College of Chest Physicians/Society of Critical Care Medicine Consensus Conference: Definitions for sepsis and organ failure and guidelines for the use of innovative therapies in sepsis. Crit Care Med 1992; 20:864-874.

-36 Izumikawa K, Nakano K, Kurihara S, Imamura Y, Yamamoto K, Miyazaki T, Sakamoto N, Seki M, Ishimatsu Y, Kakeya H, Yamamoto $\mathrm{Y}$, Yanagihara $\mathrm{K}$, Tsuchiya $\mathrm{T}$, Yamasaki N, Tagawa T, Mukae H, Nagayasu T, Kohno S: Diffuse alveolar hemorrhage following itraconazole injection. Intern Med 2010;49:497-500.

37 Lin CY, Kao KC, Tian YC, Jenq CC, Chang MY, Chen YC, Fang JT, Huang CC, Tsai YH, Yang CW: The RIFLE score increases the accuracy of outcome prediction in patients with acute respiratory distress syndrome undergoing open lung biopsy. Respiration 2009;77:398-406.

38 Gu L, Tseng SC, Rollins BJ: Monocyte chemoattractant protein-1. Chem Immunol 1999;72:7-29.

-39 Melgarejo E, Medina MA, Sanchez-Jimenez F, Urdiales JL: Monocyte chemoattractant protein-1: a key mediator in inflammatory processes. Int J Biochem Cell Biol 2009;41: 998-1001.

40 Antoniades HN, Neville-Golden J, Galanopoulos T, Kradin RL, Valente AJ, Graves DT: Expression of monocyte chemoattractant protein $1 \mathrm{mRNA}$ in human idiopathic pulmonary fibrosis. Proc Natl Acad Sci USA 1992;89:5371-5375.

41 Iyonaga K, Takeya M, Saita N, Sakamoto O, Yoshimura T, Ando M, Takahashi K: Monocyte chemoattractant protein-1 in idiopathic pulmonary fibrosis and other interstitial lung diseases. Hum Pathol 1994;25:455-463.

-42 Suga M, Iyonaga K, Ichiyasu H, Saita N, Yamasaki H, Ando M: Clinical significance of MCP-1 levels in BALF and serum in patients with interstitial lung diseases. Eur Respir J 1999;14:376-382.

43 Nakayama S, Mukae H, Ishii H, Kakugawa T, Sugiyama K, Sakamoto N, Fujii T, Kadota J, Kohno S: Comparison of BALF concentrations of ENA-78 and IP10 in patients with idiopathic pulmonary fibrosis and nonspecific interstitial pneumonia. Respir Med 2005;99: $1145-1151$ 
44 Antoniou KM, Tzouvelekis A, Alexandrakis MG, Sfiridaki K, Tsiligianni I, Rachiotis G, Tzanakis N, Bouros D, Milic-Emili J, Siafakas NM: Different angiogenic activity in pulmonary sarcoidosis and idiopathic pulmonary fibrosis. Chest 2006;130:982-988.

45 Vasakova M, Sterclova M, Kolesar L, Slavcev A, Pohunek P, Sulc J, Skibova J, Striz I: Bronchoalveolar lavage fluid cellular characteristics, functional parameters and cytokine and chemokine levels in interstitial lung diseases. Scand J Immunol 2009;69:268-274.
46 Kushi H, Nakahara J, Miki T, Okamoto K, Saito T, Tanjo K: Hemoperfusion with an immobilized polymyxin B fiber column inhibits activation of vascular endothelial cells. Ther Apher Dial 2005;9:303-307.

47 Nakamura T, Kawagoe Y, Suzuki T, Shoji H, Ueda Y, Kobayashi N, Koide H: Changes in plasma interleukin-18 by direct hemoperfusion with polymyxin B-immobilized fiber in patients with septic shock. Blood Purif 2005; 23:417-420.
8 Kushi H, Miki T, Sakagami Y, Sato J, Saito T, Tanjoh K: Hemoperfusion with an immobilized polymyxin B fiber column decreases macrophage and monocyte activity. Ther Apher Dial 2009;13:515-519.

49 Nishibori M, Takahashi HK, Katayama H, Mori S, Saito S, Iwagaki H, Tanaka N, Morita K, Ohtsuka A: Specific removal of monocytes from peripheral blood of septic patients by polymyxin B-immobilized filter column. Acta Med Okayama 2009;63:65-69. 